\title{
Shades of grey: patient versus client
}

I came here for the cut on the head and see no reason to do what you say. You are here to serve me. My taxes pay your salary." This angry outburst came from a parent when one of our emergency nurses asked her to remove her baby's clothes so she could check the child's heart rate. As I listened to the client demanding the service she wanted, I wondered if we had pushed this client concept a little too far. The baby is our patient-client and the mother is the decision-maker client who pays our salaries. Where do we draw the line?

I started medical school in an era when we only had patients. The health care providers decided what was best and told the patient what should be done. Now we talk about the clients we serve and try to involve them in deciding what is best for them. It seems progressive and the correct thing to do. Lawyers have clients. Accountants have clients. Prostitutes have clients. Doctors, the other great profession, also have clients now.

The client versus patient concept is something that I struggle with at times, and frequently discuss with other people. I found that a group of inter-professional health care providers held different ideas about the client versus patient concept. The emergency medical team said that they were always patients to them. The bleeding human being on the side of the road or the person in severe chest pain is not a client; they are patients who need + care not clients with choices. The rehabilitation team said that they were always clients as there is always shared decisionmaking. The physicians and nurses were divided and said it varies, but mostly they are patients. It was more than demand and supply. Some said it was the conno- tations surrounding the word patients and clients that made it harder to decide which term to use. Apparently, to these health care providers, clients have choices, while patients do not.

outcomes not only for the health care consumer, but also for the health care provider and the system.

Then I wondered about other subcategories. What about the elderly, the infirm, the babies or the cognitively impaired? What about the 13-year-old who refuses treatment for severe pelvic inflammatory disease? The pregnant woman with a complicated pregnancy who insists on home delivery? Who is the client and who is the patient? Does it depend on the situation, severity of illness, age of the patient or setting in which health care is provided? Should we ask our patient/clients what they think?

Most people do not choose to get ill and shared decisionmaking undoubtedly allows them to have some control in a situation that is largely beyond their control. But does this make them clients? Isn't shared decisionmaking part of contemporary medicine, regardless of the names? The client versus patient debate is not black and white, there are several shades of grey,

So I decided to divide the people we serve into the following categories in order to make it easier to decide who is the patient and who is the client. The categories were 1. Very ill or injured. 2. Not so very ill or injured. 3 . Those who think they are ill, but are well. 4. Those who think they are well, but are ill. The very ill or injured are easily categorized as patients and the not so very ill or injured can be called clients. However, those who think they are ill, but are well, and those who think they are well, but are ill should be categorized as patients although they may want to be categorized as clients. Considering as clients those who want a narcotics prescription without any assessment, or the person with angina who insists that it is indigestion, may lead to unfavourable and perhaps it's time to come up with a new word that isn't so laden with old meanings.

\section{Savithiri Ratnapalan MBBS MEd \\ Assistant professor \\ Department of Paediatrics and Public \\ Health Sciences \\ University of Toronto \\ Toronto, Ont.}

Dr. Ratnapalan is a pediatric emergency physician at The Hospital for Sick

Children, Toronto, Ont.

Have you got an opinion about this article? Post your views at www.cmaj.ca. Potential Salon contributors are welcome to send a query to salon@cmaj.ca. 